\title{
The Social Adjustment of Girls Circassian Students in State Elementary Schools
}

\author{
Yosy Maman1, Janan Faraj Falah², Elana Napso² \\ ${ }^{1}$ Ohalo College, Katzreen, Israel \\ ${ }^{2}$ The Arab College for Education, Haifa, Israel \\ Email: jananf81@gmail.com
}

How to cite this paper: Maman, Y., Falah, J.F. and Napso, E. (2018) The Social Adjustment of Girls Circassian Students in State Elementary Schools. Open Journal of Social Sciences, 6, 230-245. https://doi.org/10.4236/jss.2018.61017

Received: December 19, 2017

Accepted: January 27, 2018

Published: January 30, 2018

Copyright ( 92018 by authors and Scientific Research Publishing Inc. This work is licensed under the Creative Commons Attribution International License (CC BY 4.0).

http://creativecommons.org/licenses/by/4.0/

(c) (i) Open Access

\begin{abstract}
The Circassians are Sunni Muslims, originated in the Caucasus, a part of the former Soviet Union. During the rule of the Ottoman Sultan Abd al-Hamid II in the 1860s, many Circassians joined the Ottoman Army; some of them were settled in Israel and worked as farmers or as the maintainers of the Hejaz railway's route from attacks of Bedouin tribes (Shabsu, 1993) [1]. Since 1948, Circassian men had begun serving in the Israel Defense Forces on the order of their leaders. The Circassians live in two villages in the Galilee area, in the Village of Kama and in Rihania. These two villages have elementary schools, in which, most of the teachers are Circassians. They belong to the Druze Education Department that is separated from the regular Israeli educational system. At the end of the elementary school phase, the Circassian pupils go to Jewish schools. This article emphasizes on the difficulties of the Circassian students, who are forced to leave their local school in the village to a Jewish one, to be adjusted to new society and culture, while preserving their own culture and origin. The emphasis would be on the viewpoint of the Circassian students, the extent of adjustment and the option to develop a "built-in model" that would facilitate the absorption of these students (of different origins and cultures) at school. Furthermore, the article emphasizes on the importance of school's staff exposure to students' standings, in a manner that would lead towards sensitivity and empathy to these special ethnic groups of students in school.
\end{abstract}

\section{Keywords}

Circassian, Adjustment, Students, Elementary Scole, Israel

\section{Historical Background of the Circassians}

The origin of the Circassians is in the Caucasus region. Their ancestors are part 
of two main ethnic groups of "Adygeans" and "Kabardians" who became Sunni Muslim in the 18th century. Their language is Adyghe as is spoken in the Caucasus, which is partly learned in school and mostly common language within the family, for the formal language at schools is Russian. It is noteworthy that since the fall of the Soviet regime, the Circassians have begun to develop their nationality that is emphasized on a rivalry between the Adyghe language and the Russian one on a daily usage (Adnan, 1993) [2]. In the 18th century, due to the defeat of the Ottoman army to the Czar, a massive immigration began to the Balkan, Syria and Turkey. During the period of the Sultan Abd al-Hamid II in 1860s, many Circassians joined the Outman army and were settled in the land of Israel and were employed as farmers and as the guardians of the Hejaz railway's route from the Bedouins' attacks (Shabsu, 1993) [1]. There are 3 million Circassians in Turkey, about 70,000 in Syria, approximately 50,000 in Jordan and about 3000 in Israel, living in the village of Rihaniia at the Upper Galilee, which was founded in 1869, and in the village of "Kamma" in the lower Galilee, which was founded in 1876 (Achmos \& Hatokai, 2000) [3].

The ethnic identity is extremely important for the Circassians. Thus, they maintain the Adyghe language, the history and heritage, the collective sense of destiny with other Circassians' communities in the diaspora, and their loyalty (Khalhavaze) to the family and village, yet, still maintain loyal citizenship to the State of Israel.

It is important to note, in relation to this study (of students' adaptation) that Circassians have common belief "who was born Cherkassy would die one", a statement that highlights their "cultural expectation" to remain loyal to their cultural ethnic origin. Another statement "Be Cherkassy at home and an Israeli outside home", also emphasizes their efforts to be part of the State's life.

"Kafkaf" School (false name for ethical reasons), is an agricultural boarding school that was founded in 1933. For 20 years, only boys (who were selected carefully) studied at school. The rigorous admission tests and the high level of studying were intended to prepare the graduates to study Agronomy in prestigious academic institutions in Europe. Over the years, the school had changed its "characteristic", and today it contains over 1650 students, yet only 250 are part of the boarding school. The boarding school operates under the supervision of the Boarding School Administration within the Israeli Ministry of Education, and much appreciates for its great emphasis on Israeli nationalism and the love for the country. From the year 2000, school has become experimental with a focus on multiculturalism. School treats multiculturalism as fundamental issue, and believes that the "right" coping with the different multicultural-ethnic groups, would lead to reduction of social gaps and prevention of violence, with a clear message of "we all differ one from each other, yet we all have a place here".

The student population in school is a microcosm of the Israeli society. The daily routine at school has led to an experimental program, aiming to develop a dialogue between cultures, without been subjected. The experimental program is developed for the $7^{\text {th }}$ to $12^{\text {th }}$ grades; it includes varied educational aspects of for- 
mal and informal education in school and in the boarding school, that multiculturalism is the basis for all its programs. Every student is entitled to present his culture without fearing of rejection or criticism. From this supportive point of view, a student is able to learn about different cultures without being judgmental, an element which often becomes an obstacle for proper integration. Once a student feels appreciated, the "other" does not seem threatening and there is no need in isolation. The experimental program includes all school aspects and aspires to involve communities, which are in relation with school, parents and other schools.

The boarding school has agricultural farm with stall, barn, stable, plantations, orchards, fields and research center. The village offers its students sports and cultural facilities: playing field, audio-visual hall, library, music center, studying room, art workshops, art classes, cyber classes, etc. School has 130 teachers and another 70 employees. In recent years, "Kadury" is a magnet to students all over the region, and its number of students is increasingly rises each year. The school population is diverse and includes students from the communities of the Lower Galilee Circassian villages, Bedouins, Arabs, Druse and new Jewish immigrants from Ethiopia and CIS countries.

\section{Research Methodology}

The study is a qualitative research of "case study", with a focus on detailed description of phenomenon (Stake, 2005) [4], (Behrendt, 2017) [5]. Thus, a researcher uses an "holistic approach" (Abuhav, 2013) [6], focusing on uncovering, learning and understanding the inner world of one's "Subject", from the subject's perspective (Toval-Mashih, 2013) [7], (Denzin \& Lincoln, 2000) [8] by this approach, behavior is examined by the Subject's origin, that is to say, definitions, beliefs, values and ideologies (Pelto \& Pelto, 1978) [9]. Most of the research field work is based on ethnographic, structured in-depth interviews as a primary source of information, that enables the interviewee to tell his story freely while remaining focused on the research questions (Kapel-Green \& Mirsky, 2013) [10]; (Shkedi, 2011) [11]; (Fontana \& Frey, 2005) [12]. The Interviews includes 6Circassianstudents from the village of "Kfar Kama", describing their personal experiences in school (Spradley, 1979) [13]. The ccoordination of interviews was by phone and the interviews were conducted at their home for about 50 minutes, and are documented in writing. It should be noted that this High School takes in Junior High School of "Kfar Kama Village", therefore, the interviews included students at the end of the $10^{\text {th }}$ grade who are able to provide profound perception of their social, cultural and educational experience.

\section{The Interviewees' Origin}

As stated, the interviews of the 6 students (Table 1) were "structured" with pre meditated questions, by the following order (Hugh-Jones, 2010) [14]; (Wilson, 2016) [15]: 
Table 1. The interviewees' origin.

\begin{tabular}{ccccccc}
\hline Number & Name (fake) & Gender & Age & Village & Class No. & Subject of Study \\
\hline 1 & Kevin & Male & 15 & Kfar Kama & 6 & Mechanics \\
2 & Sophie & Female & 15.5 & Kfar Kama & 5 & Biology-Chemistry \\
3 & Lee & Female & 14.5 & Kfar Kama & 4 & Physics-Biology \\
4. & Sau & Female & 15 & Kfar Kama & 3 & Computers-Physics \\
5 & Nir & Male & 15.5 & Kfar Kama & 2 & Sports \\
6. & Lully & Female & 15. & Kfar Kama & 1 & Biology Ecology \\
\hline
\end{tabular}

\section{Before the Transition to "Kafkaf School" (The First Time Phase)}

1) Did you fear the transition? What were your concerns?

2) Describe your talks with the family during this time.

3) Did you have prior knowledge of school from other Circassianstudents? If so, what kind of knowledge?

4) How did you imagine your future encounter with students from other cultures?

\subsection{During the Transition (The Second Time Phase)}

5) Describe your first days at the new school.

6) Did other students assist you coping with difficulties?

7) Describe the nature of your relationship with your educator and one's contribution to your adjustment.

\subsection{Conclusions \& Future Perspective (The Third Time Phase)}

8) Who are your friends, explain why?

9) What would be your best advice to new Circassian student?

10) What would be school's "best role" in absorbing students of different cultures?

11) What did you not had to give up culturally speaking?

12) Do you feel you have changed due to the encounter with the Israeli culture?

After the data were collected, they are analyzed carefully in accordance with the leading categories of each question in the questionnaire. This process of content analyzation of each question is done by the Emic Approach (Givaton, 2001) [16]; (Miles \& Hubermaan, 1994) [17], namely, arranging the topics and sub-topics out of the answers (Glaser\& Strauss, 1967) [18], (Miles \& Huberman, 1994) [17], (Bawa, 2017) [19]). Tzabar (1995) [20]. argues that this process is made without shortcuts; the researcher examines the evident text, seeking for the repeated, important and noticeable phrases and statements, phrasing the categories, selecting the analysis pieces and placing the content segments (Shkedi 2010 [21]; Charmas, 2005 [22]; Perakyla, 2005 [23]; Shanthi, 2017 [24]). Shkedi (2003) 
[25] adds that in the course of analyzation of data, the researcher already associates the words and phrases into categories that become meaningful merely in relation to other categories.

\section{An Analysis and Interpretation of Students' Answers and Positions}

In this part of the paper, I would like to present students-interviewees' descriptions in relation to the categories that were developed out of the answers. At the same time, I would present the "researcher's voice" (Goldblatt, 2013) [26]. In order to facilitate the reading of the students' positions and attitudes, the analyses, including the researchers' interpretation were typed in different font. It is marked with the sign $\left(^{*}\right)$.

\subsection{Before the Transition to "Kafkaf School" (The FIRST Time Phase)}

\section{The Students' concerns:}

Most interviewed students were concerned about the transition. The first concern is related to failing to adjust socially, as Lully describes:

"The mentality differs from the one in the Circassian school, socially speaking. I was afraid that I won't be popular and my classmates won't accept me, for I come from different culture. I didn't know how to cope with the new environment-a new place with new people that might not like me".

${ }^{*}$ For Lully, The transition to new environment is beyond mere physical change, it includes also a social aspect-a transition into a certain social frame with different norms and codes that she does not familiar with, unlike her classmates. She makes a connection between "social acceptance" and "origin of culture". And I ask myself whether school, in general, is able to support new students in the phase of transition, and a student from different cultural background in particular?

The second concern is failing in studies, as Sophie describes:

"Fears from the compulsory subjects such as Bible, Linguistics that we hadn't learn in the old school, and do not have the basis or proper background. I fear that I would not manage to succeed academically, fearing of failure".

$O$ A. does school is able to prepare the Circassian students in advance, before entering school? When is the right time?

B. The second issue is the importance of strengthening the relationships between the schools-the former one and the new one, in terms of curriculum sequence.

C. If there is a gap, due to lack of expose of the student to certain contents, it might lead to lack of academic achievements and to decline of the student's so- 
cial status, the student can no longer be seen as diligent as in the past at the village.

Sau displays a different attitude: "I was afraid that the system would not meet my skills or my personal needs, and for that reason, maybe I did not make the right decision in choosing this schoop'?

Sau's point of view reveals personal concern; hence, she refers great importance to succeeding in school. At this point it is important to emphasize that school should endure students' "criticism".

Two students had no concern at all: "I personally did not fear the transition, for I like changes, new environment and new people".

${ }^{*}$ As educators, we must remember that students do not share the same opinions. The statement "love changes" could apply to students' previous experience, and enables the researcher to form a profile of readiness towards the encountering with new cultures and societies, and hence, to develop a proper model to deal with the absorbtion of new students from different cultural backgrounds.

\subsection{Discussing the New School Issue at Home}

It is possible to map the issue on the sequence of not having a conversation at all, to pressuring the student.

\subsection{In Cases of Not Having a Conversations at Home}

"We haven't discussed specifically the issue, for my parents know me very well, and were positive that I could handle any situation".

\subsection{General Conversations about School}

"There weren't direct conversations about school; it was random talks, for I wasn't the only member of the family to attend this schoop".

\subsection{Discussions about Desirable Study Courses}

"My family has advised me which courses to take".

\subsection{Attempting to Address Future Questions}

"Our conversations aimed to provide proper answers of the following questions-Is school good? Who attends it? Do most students from the village attend this school? What about transportation? And the important issue of-the distance from the village to school."

\subsection{Encouraging the Child at Home}

"My family supports me and even encouraged me to go to school a year before, for they recognize the importance in pre-adjustment and being exposed as early as possible to reality surrounding us-to the Jewish majority and the official Hebrew language, all for the sake of my future development". 


\subsection{Pressuring the Child}

"My parents pressured me to attend this school, for it has regular transportation. I wanted to go to another schoop".

${ }^{*}$ Alongside of the family passivity on this sequence, "a functional intervention" due to economic considerations of profit and loss (transportation for instance) are done against future professional and social ones (development and openness). It is apparent that parents refer great importance to preliminary "social training", for they recognize the importance of adjusting to the broader Israeli society and the need in breakthrough the safe, well known "social circle" of the family, friends, community/village. It is important that school would acknowledge that the family can become the student's "supportive link", thus, to improve and maintain relations with the parents, to join forces in preparing the child mentally to the transition.

\subsection{Pre-Knowledge of School, Obtained by Other Students}

The interviewees report of receiving both positive and negative recommendations.

Nir emphasizes that "Students in Bagrut program say that school level has improved. They highly recommend the system, the teachers, and the unique courses in school: agriculture classes, home economics and stable. Many Circassian students do not recommend school, due to its academic level and the social aspect-those students study in vocational course programs, and therefore do not recommend schoo?".

${ }^{*}$ Apparently, perceiving school positively or negatively is influenced by the nature of the program in which the students are in (standard academic program or vocational one), regardless the student's cultural origin. We believe that all "senior" students are "agents of socialization".

The senior students provide information about school's population:

"School is made out a blend of cultures: Ethiopians, Arabs, Circassians, Russians, Druze, Ashkenazi Jews, Yemenite Jews, Moroccan Jews, etc. It's very interesting to meet students of different origin and to learn about their cultures".

*School is not made of "one cultural group", but of "sectoral blend" of many cultural groups. The Ashkenazi Jews are exceptional; this is the only sector which is not subdivided. The statement "It is very interesting to meet and learn about different culture" is highly important to School, for it emphasizes the students' attitude towards intercultural encounters as intriguing and challenging. This could be the basis for further pedagogical interaction. The encounter with the "different cultures" creates positive interaction that we should use to exploit as leverage towards breaking of barriers and prejudice towards mutual stimulation, deepening the learning, developing openness, and forming pluralistic approach towards dialogue diversity, uniqueness between the different ethnic groups. 
Particularly interesting is Kevin's statement regarding his village friends that recommended school:

"Students in "kafkaf seems to be popular, for they dared to replace their

Circassian milieu into another, this is why we wanted to move to another

class as quickly as possible, in order to bridge the gap between us".

*The term "Popular" has several meanings: A. It refers those students who manage to break through the "social-cultural territorial circle". B. Adjustment reflects a transitioning from one state to another. C. The "adjusted student" is active, regardless the role of the "senior-hosting student".

D. It is important to examine whether a "students of certain culture/group" give up their "codes of culture"?

E. The role of the school in this process.

\subsection{Thoughts on Future Encounter with Students from Different Cultural Origin}

Future meeting with students of different cultural origin is perceived positively and negatively.

As Lulli describes, "I imagined a meeting in which everyone would be friend$l y$, that we would be welcomed warmly aiding us in the transition".

Sophie adds, "I am an open person who bonds very quickly, regardless the cultural origin of the student. I remember that I imagined the meeting positively, as a chance to learn with different students of different background. I liked the idea that I would learn things about others."

*Luli presents a position whereas the "hosting-senior students" plays an active role in the process of adaptation that is to say, the "burden of adjustment" falls mainly on one's shoulders. While Sophie's description indicates that the "adjusted (new) student" has a key role in the process (one should be open, creative, friendly, quick learner). The question would be then, whether the school should be based on Sophie's approach of "intercultural encounters" as the educating, contributing element in developing and fostering a positive social climate among students?

Sau displays negative attitude, "I thought that other students would not be interested to meet Circassian students or to get to know us or even accept us. I was sure that I would not be popular, for we're very different".

*Sau disqualifies in advance her adjustment on the grounds of "cultural difference". Thus, it is necessary that school would examine on regular bases methods of "becoming active social agent", in order to prepare the "social grounds" for the adjustment of the new differ cultural students, to encourage cooperation and decreasing of gaps.

\section{The Phase of Transition (The Second Time Period)}

\subsection{The First Days at School}

This is Nir's description, "The first few days were confusing, we didn't know 
where the classrooms are, and the teachers. It is a large school, very different from what $1 \mathrm{~m}$ used to, the environment is new and unfamiliar, and school is managed in a different style".

Sophie adds, "I realized that they put me in class with none of my friends, although we joined at the same year and wanted to be at the same class. I knew how to deal with it and overcome the difficulties. The teachers made us feel at home".

*For the new student, the "landing" is new and unfamiliar, and therefore, one feels disorientated and confused in physical terms. We offer to solve this problem by initiating a tour for new students already in their great vacation, to provide the new students brochure both in the Hebrew and Circassian languages. The material will include school's chart and list of teachers' roles. As for the social aspect, Sophie's description indicates of "social detachment" from the previous friends, the "popular group", who made her confident. This is the point to consider put together in class at least two students from the same former class or village, in order to alleviate the first phases of adaptation and to contribute to a better feeling of the new student (of different culture). Her narrative indicates that a teacher should be the "mediator". We believe that this should be the teacher's perception of role. It should be done consciously and systematically by every teacher, whether a teacher is attentive or sensitive enough towards his/her students.

\subsection{Students Who Assisted Other Students to Deal with Their Difficulties}

The analysis of the students' interviews suggest that the leading difficulty of new students from different cultural origin is social, as Lully reveals,

"My biggest problem was that all the students in my class know each other and are friends for years, except for myself".

Kevin adds, "Some students in my class feared me at the beginning because they were hit by their Circassians classmates in junior high, and that was their entire knowledge of Circassians"...

Students who assisted their new classmates represent a "supportive social circles", as follows:

The Sister-"My sister had studied here before me, and she assisted me, meaning fearing different culture and mentality".

Old school friends-"I wasn't alone, I had my friends from the old school. 5 Circassian girlfriends joined me in my new class. It made it easier, we assisted each other to adjust, for we all were "in the same boat".

Circassian friends at the same grade- "We've always been a big group in our grade at school, we were united and helping each other out, boys and girls together. I always share my thoughts and difficulties with them. We were constantly together and that's why we have never tried to meet other students, for we felt comfortable within our group".

Jewish girlfriend-"I have a Jewish friend, and she was the one that helped me dealing with all the difficulties, even the language". 
*It is important to recognize that former "social supportive circles" differ from the ones of the new school. These former circles are mainly represented by student from the same ethnic origin the sister, previous school friends, and students from the same sector. The sister plays the role of an "active agent of socialization" by guiding and directing sister how to cope with the new environment. At this phase one should examine the cases a student does not have sisters or brothers that had studied at the same school, who then would fulfill this important function?

The old friends from the former school provide a sense of shared fate ("being in the same boat"), due to their mutual, united origin and culture. This element only increases the cohesion of the ethnic group and places it in a "different social-cultural territory". For us, as educators, It is essential to understand the student's perspective of better stay together than being alone, as for the Circassian group, it becomes a "fly in the ointment", on the one hand, the group's unified cultural identity is a source for "collegial assistance", on the other hand, it creates a "barrier", preventing the breaking of social barriers, due to this social segregation. A friend, from a different cultural background, in this case the "Jewish friend", plays an important role of "translator", "mediator" or a "social and cultural tutor".

\subsection{The Relationship between Students-Teacher Educator and One's Contribution to the Students' Adaptation}

The relationship between the Teacher-educator and students from a different cultural background can be categorized by the following sequence:

Minimal relations - “I hadn't personal relationships with my teacher, she merely knew me by my name".

Equal relations-"My teacher knew us all, she made effort for each one of us and understood us all, regardless my ethnicity or different culture, we are all equal and special for her".

"I have a male Teacher, tall and nice, he respects us all equally, yet it was hard for me to communicate with him, for I didn't think I could share my difficulties with a man. I am an introverted girl."

Increasing awareness towards Cherkassy culture-“ $M y$ Teacher-educator ran several lesson on Circassian culture and life. I have good relationship with my teacher, for she lives in the area and knows Circassians culture, life, limitations and codes of behaving".

\subsection{Maximum Relations}

"My teacher helped me to adjust, he supported me and I felt that someone is actually listens me". "I kept in touch with my teacher, she helped me in every aspect and persuaded the students not to fear me".

*According to the interviewees' narrative, there are two models of teacherstudent relationships, the first indicates of minimum relations, knowing the stu- 
dent only by name, and the second one, lies in the teacher's personality that determines the nature and the duration of the relationship ("attentive", "supportive" or "understanding"). This conception of role contains "broader spectrum" of thinking and acting. It is a result of teacher's comprehension of the class's cultural heterogeneity. The teacher's starting point is active, one knows the "cultural codes" (what is aloud or forbidden) and running lessons of the Circassian tradition and culture.

It should be noted that we, the educators, have great responsibility and moral obligation to respect the "Other", the different "cultural legacy" that differs other ethnics, and to convey tolerance to all students.

\section{Conclusions \& Future Perspective (Third Time Period)}

\subsection{Students' Friends}

The interviewees state that their friends at school are also Circassians. Sau: "We are together since kindergarten. After consulting each other, we all chose to take the same study courses, in order to keep being together. We are friends from childhood". Lully is adding: " $P m$ a friend of Circassian as a sign for solidarity in my community. We became friends in 'Kafkaf' school'.

*It is clear that the ethnic group is a source for strength for the student-individual. Furthermore, the individual prefers scarifying for the sake of one's group. The first example emphasizes the "social togetherness", in this case, the social aspect becomes first (Circassian friends), due to the development of relationships over time, within the external common layer of culture. The second example emphasizes "culture"; the making of new friendships is made on common "cultural-heroic" basis, as a source of identification and "pride".

In contrast, NIR describes: "I have also Jewish friends that I play with only at school; I cannot meet them outside school, for they live in other villages".

*The school is rigid "surround" territory. The interactions between students of different ethnic groups develop as a result of joint encounters in this territoryclasses and breaks. In this case, it appears that "friendships" do not leave the boundaries of school, due to the geographic distance of student, living at different villages with different cultures and origins. We believe that this undermines social stability, and therefore, requires profound thought-how to develop relationships among students of different villages and different ethnic origins, beyond school time in general, and among student of the same village who does not share the same ethnic origin/culture.

Sophie's statement is specifically interesting, "Over time, $P$ ve made a lot of friends that are not Circassians. I have Jewish friends that I learn from, particularly one friend, but $1 \mathrm{~m}$ not giving up on my old Circassian friends, although our relation has weakened in time."

${ }^{*}$ This is an example that friendship is allowed between students of different cultures, it mainly depends on the student's willing to learn about "other" ("I learn", "I get"). The student becomes active in the course of expanding her "so- 
cial circle" ("I acquired"), simultaneously, her relationship with her Circassian friends have weakened. In this case, "social adjustment" has instrumental-beneficial aspect; this is the reason why it is much more dynamic than "cultural adjustment", for culture is aimed only for its people, hence, more resistant to changes.

\subsection{A Tip to the New Circassian Student}

The advice that students chose to give the new Circassian student was divided into three categories: personal, social and cultural. "It's normal, you can overcome anything with little effort and desire. Every beginning has difficulty, a lot of doubts and fears, and yet, it also challenges. Let nature takes its course and, you'll see that things will get better, just hope for the best, be patient, optimistic and have a will" (personal). "It is important to adjust fast, for it is difficult to survive school without it. Try to fit in right from the beginning, don't be shy, try to get to know everyone, to make friends with as many people as possible" (social). "Don't forget where you come from, your education and values from home. Just be yourself" (cultural).

*The first statement indicates of accepting "reality". In this case, adaptation is an expression of the individual's inner strength (efforts, desire, patience and optimism). The second statement expresses a social process that a student invests in order to adjust (to fit in, open, acting and making friends). For the student of foreign ethnicity, adaptation becomes an act of "survival". The third statement emphasizes the cultural aspect, thus, in the phase of adjustment, it is recommended not to abandon common "cultural codes".

It is important to understand that a student in general, and a student of different culture origin in particular, both have to adjust to the new place"school", this is the same process that immigrants undergo in foreign country, it is a kind of "internal migration" which requires strength, great efforts and patience, since the process takes time.

\subsection{School's Desirable Role in the Student's Adaptation}

Luli states "Students must remember that kids like us has different culture, education and values, therefore, school should prepare its students to accept different cultures, for we all live together and should know the special and important staff, and in this manner, to respect each other". Sau adds, "The main role of school is to form 'social integration'. School should organize and multi-cultural activities to assist and accept the students, to enable gaining knowledge about the origin and culture of the 'Other'. This should be made through 'introduction day', making of ethnic food, presenting the language, customs and behaviors".

*These statements indicate of two phases for creating a desirable activity at school-the phase of "preparation" of the students' absorption and the phase of social bonding during the year. Thus, school becomes an "active agent for socialization", at first it prepares the mature old students-"the absorbers" to wel- 
come the new ethnical students "the absorbed", in this manner, the adjustment of the new students becomes easier. In the second phase, School runs a "cultural pavilion"- a display of varied cultures and ethnic groups at school, students become exposed to diverse cultures, and school actually provides platform to all cultures, towards mutual respect between students in school.

\subsection{The Circassian Heritage}

Lee states that "There is no concession on the part of culture, especially if its foundations are solid. The language, clothing (not too daring), self-respect-all by Circassian codes". Kevin adds, "P ve never felt that I had to give up something in order to be popular, on the contrary, my stubbornness only led to greater respect, my Jewish friends have learned to speak Circassian a little beat, welcoming me in my language".

*The Students' statements were decisive ("no concession") and display strong willpower to maintain their "culture", its "heroic past" and "legacy". Culture is perceived in terms of language, cloths and dignity, culture is not perceived as an "independent entity" but as an expression to preserve its codes and ethics (" $A$ solid foundation") in the course of the encounter with the different culture. The conclusion is that cultural encounters are two-way and educating: one student signals to the other in codes, and the massage is transferred. Hence, culture "becomes alive" by both sides.

\subsection{The Results of the Encounter with the Israeli Culture}

The opinions regarding this issue are varied:

No change - "I wasn't changed, I remained the same".

Not to be affected- "I pretty much try not to be affected by another culture".

Relationships-“Every encounter creates an interaction, learning about reality surrounding us".

Learning about myself- "Three years with people of different culture has influenced me. I have learned that we can improve".

Expanding knowledge-"I have expanded my knowledge of the Israeli society, its traditions, language, cloths and mentality. This is the change, although at home we hear the "Hagashash Hachiver", songs of the military bands, Yoram Gaon, for my father loves Israeli music".

Maturity assource for a change-" When I was young I knew only what is in the boundaries of my village. The transition to the new school gave me knowledge about people, life, different perspective, high level of studying and an attempt to create new relations with new friends. It made me grow-up. The change was positive and I managed to gain confidence, something which I never had before. I believe that a person could change in a different environment".

${ }^{*}$ The Opinions are varied and differ from student to student, an element which proves that intercultural encounter affects students differently. In addition, the interviewees recognize the difference between the Circassian culture and the Israeli one, "the other". The students' statements describe the term 
"culture" in two aspects: "external" - a culture as a combination of customs, language and cloths, while the other refers to "internal" processes-a culture which emphasizes different codes of behaving, perspective and mentality. This also indicates that "intercultural encounter" has educating element, thus, the exposure and interaction with another culture lead initially to breaking of boundaries of the "territory" of the origin culture, and continues changing. We believe that it is vital that school would acknowledge that mutual exposure to various cultures at school can contribute the individual, as presented in this article.

\section{Epilogue}

This research, both in the theoretical aspect and in the phase of implementation has great contribution. On the theoretical aspect, the paper "portrays" the term "adjustment" in different light:

Pre interaction-The student is in "protective social circle" of the family, friends and the community, within a unified cultural identity and the "heroic legacy" of the Circassians community.

The encounter-is the interaction with the different culture, with the provide/ non-providing support by the "agents": friends, parents, brothers, senior Circassian students, new friends.

The results of the encounter-The first option is "social segregation" and becoming friends of students from the same ethnic-cultural group, creating a rigid "social territory" within school. The second option is to integrate with school's society, yet relying on their internal strength, will, patience and optimism along with "social activism"-openness, social networking and learning. From our point of view, the students have essential role in the course of integrating, opening up to new, different environment, in addition to maintenance of their Circassian "cultural core" (the past, the codes and the mentality).

As regards to the practical aspect of the analysis of the students' attitudes, we offer this model to school and the community, as follows:

Stage 1-Preparation towards the transition to school: to create interaction on regular basis between the new school and the former one, by the teachers' involvement. Teachers of both schools would conduct professional meetings in order to remain updated in the learned pedagogical contents, to maintain continuity and to minimize gaps in certain courses. We suggest that the "observing" teacher would learn about his students' culture and origin, be exposed to future conflicts on grounds of the differentiations, and to the unique cultural codes of the new students that about to enter school. At the same time, school should initiate students' encounters, to create integration and acceptance of the "other" through mutual tours to both schools and other mutual activities.

Stage 2-The transition and absorption in the new school: to give the students a school brochure-amap, syllabus, list of teachers specifying their major, and a list of school staff in several languages. To invite parents and student to information day before school opens. Ensuring that several students from the 
same ethnic group would be set together in class, in order they would not feel isolated, and to attach senior student to the new student to be one's mentor.

Stage 3-Routuine: Increasing teachers' awareness towards playing an active role in the process of adjustment of the new student, furthermore, to perceive intercultural encounters as challenging, intriguing, educating and empowering for all parties.

It is important that educators and teachers would treat the "culture of origin" as equal and legitimate on daily basis, and the more we would be exposed to the issue, the more we understand the culture of the "other" and treat one respectively, willing to accept the difference. We also recommend continuing the students' interaction and integration beyond school hours, to encourage friendships and senior students' mentoring.

\section{References}

[1] Shabsu, A. (1993) The Circassian History \& Heritage. The Ministry of Education \& Culture, The Circassians Committee for Education, Israel.

[2] Adnan, G. (1993) Radga Cicassians. Shefa'Am Publications, Kafr Kama.

[3] Achmos, S. and Hatokai, R. (2000) The World of the Circassians: The Village of Kafr Kama and the Wadiof Haifa.

[4] Stake, R.E. (2005) Qualitative Case Studies. In: Denzin, N.K. and Lincoln, Y.S., Eds., The Sage Handbook of Qualitative Research, 3rd Edition, Sage Publications, London, 443-466.

[5] Behrendt, M. (2017) Examination of a Containing Active Science Club: A Case Study. Science Educator, 25, 82-87.

[6] Abuhav, A. and Meltzer-Geva, M. (2013) Facing the World \& My Inner World: Teaching of the Qualitative Research in Education. In: Hazan, A. and Notov, L., Eds., Teaching the Qualitative Research: Principles \& Implementations, Ayalon Print, The Mofet Institute, 53-77.

[7] Toval-Mashih, R. (2013) Challenges, Difficulties \& Solutions in Teaching Social Sciences Qualitative Research. In: Hazan, A. and Notov, L., Eds., Teaching Qualitative Research: Challenges \& Principles of Implementation, Ayalon Print, The Mofet Institute, 23-51.

[8] Denzin, N.K. and Lincoln, Y.S. (2000) Introduction: The Discipline and Practice of Qualitative Research. In: Denzin, N.K. and Lincoln, Y.S., Eds., Handbook of Qualitative Research, $2^{\text {nd }}$ Edition, Sage Publication, London, 1-28.

[9] Pelto, P. and Pelto, G. (1978) Anthropological Research: The Structure of Inquiry. Cambridge University Press, Cambridge. https://doi.org/10.1017/CBO9780511607776

[10] Kopel-Green, A. and Mirsky, Y. (2013) This Place is in My Nature Reserve Portrait of Mifneh School in the Eyes of His STAFF. In: Alpert, B. and Shlasky, S., Eds., The Class \& School on Closer Inspection-Ethnographic Studies, The Mofet Institute, Tel Aviv, 108-140.

[11] Shkedi, A. (2011) Meaning behind Words: Methodologies in Qualitative Research in Practice. Tel Aviv University, Tel Aviv.

[12] Fontana, A. and Frey, J.H. (2005) The Interview: From Neutral Stance to Political Involvement. In: Denzin, N. and Lincoln, Y.S., Eds., The Sage Handbook of Qualitative Research, 3rd Edition, Sage Publication, London, 695-727. 
[13] Spradley, J. (1979) The Ethnographic Interview. Rinehart the Kaduri School, New York. http://www.kadoorie.org.il/Content.aspx?id=10

[14] Hugh-Jones, S. (2010) The Interview in Qualitative Research. In: Forrester, M.A., Ed., Doing Qualitative Research in Psychology, Sage Publications, London, 77-97.

[15] Wilson, A. and Onwuegbuzie, A. (2016) Using Paired Depth Interviews to Collect Qualitative Data. The Qualitative Report, 21, 1549-1573.

[16] Givaton, D. (2001) A Theory Supported in the Field: The Meaning of the Data Analysis Process and the Construction of Theory in Qualitative Research. In: Tzabar, N., Ed., Traditions \& Trends in Qualitative Research, Dvir, Tel Aviv, 195-228.

[17] Miles, B. and Hubermaan, M. (1994) Qualitative Data Analysis: An Expanded Sourcebook. Sage Publication, Thousand Oaks.

[18] Glaser, B. and Strauss, L. (1967) The Discovery of Grounded Theory: Strategies for Qualitative Research. Aldine, Chicago.

[19] Bawa, P. (2017) Making Sense of Making Meaning, the Semiotic Way: Emotional Journey of a Novice Learner. The Qualitative Report, 22, 73-104.

[20] Tzabar, N. (1995) The Qualitative Research in Teaching. Modan Publications.

[21] Shkedi, A. (2010) A Theory Supported by Narratives: Constructing of a Theory in Qualitative Research. In: Kassan, L. and Cromer-Nevo, Eds., Qualitative Data Analysis, Be'er Sheva University of the Negev, Beersheba, 436-461.

[22] Charmaz, K. (2005) Grounded Theory in the 21st Century: Application for Advancing Social Justice Studies. In: Denzin, N.K. and Lincoln, Y.S., Eds., The Sage Handbook of Qualitative Research, 3rd Edition, Sage Publications, London, 507535.

[23] Perakyla, A. (2005) Analyzing Talk and Test. In: Denzin, N.K. and Lincoln, Y.S., Eds., The Sage Handbook of Qualitative Research, 3rd Edition, Sage Publications, London, 869-886.

[24] Shanthi, T. (2017) Teacher Empowerment: A Focused Ethnographic Study in Brunei Darussalam. The Qualitative Report, 22, 47-72.

[25] Shkedi, A. (2003) Touching Words-Qualitative Research: Theories \& Implementation. Tel Aviv University, Tel Aviv.

[26] Goldblatt, H. and Bend, T. (2013) Between Understanding \& Insights: Reflective Teaching in Qualitative Research. In: Hazan, A. and Notov, L., Eds., Teaching Qualitative Research: Challenges \& Principals for Implementation, The Mofet Institute, Tel Aviv, 209-241. 